\title{
Exploring implementation of a nationwide requirement to increase physical activity in the curriculum in Danish public schools: a mixed methods study
}

Sofie Koch ${ }^{1 *}$, Charlotte Skau Pawlowski ${ }^{1}$, Thomas Skovgaard ${ }^{1,2}$, Natascha Holbæk Pedersen ${ }^{3,4}$ and Jens Troelsen ${ }^{1}$

\begin{abstract}
Background: In 2014, the Danish Government introduced a wide-ranging school reform that applied to all public schools in Denmark. A distinctive feature of the reform was that it became mandatory to implement an average of 45 min of daily physical activity within the curriculum. Using the RE-AIM framework as an evaluation tool, the objective of the current study was to evaluate the reach, effectiveness, adoption, implementation, and maintenance of mandatory physical activity within the curriculum at ten Danish schools.

Methods: A complementary mixed-methods approach using accelerometers, questionnaires, and semi-structured interviews was conducted. A total of 10 schools were invited to participate, including 846 students, 76 teachers, and 10 school managers on various levels. Students were invited to wear an accelerometer for seven consecutive days. Teachers were invited to participate in a questionnaire, and school managers were encouraged to take part in a semi-structured interview.

Results: Results showed that, on average, $45.2 \%$ of the students were active at least 45 min daily within the curriculum. Teacher and school management interest in physical activity, competencies development, and shared decision-making were identified as central factors for adoption of the requirement. Scheduling physical activity within scheduels and collaborations with external parties were found to influence implementation. Finally, internal coordination, motivated school staff, and school management priority were identified as central factors for maintenance.

Conclusions: This study provides an evaluation on a nationwide physical activity requirement in Danish public schools. When introducing a wide-ranging nation-wide requirement on physical activity within the curriculum, school managers need to prioritize and support the implementation process. Teachers need to be involved in the decision processes in order to ensure motivation and local ownership. The study also highlights the benefits of an internal coordinator as well as development of a shared strategy among schools, municipalities, and other stakeholders in order to succeed with the implementation.
\end{abstract}

Keywords: Physical activity, Implementation, School setting, RE-AIM, Mixed methods

\footnotetext{
* Correspondence: skoch@health.sdu.dk

${ }^{1}$ Research Unit for Active Living, Department of Sports Science and Clinical Biomechanics, University of Southern Denmark, Campusvej 55, 5230 Odense M, Denmark

Full list of author information is available at the end of the article
}

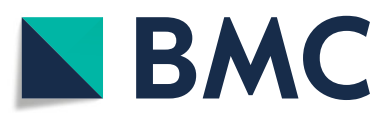

(- The Author(s). 2021 Open Access This article is licensed under a Creative Commons Attribution 4.0 International License, which permits use, sharing, adaptation, distribution and reproduction in any medium or format, as long as you give appropriate credit to the original author(s) and the source, provide a link to the Creative Commons licence, and indicate if changes were made. The images or other third party material in this article are included in the article's Creative Commons licence, unless indicated otherwise in a credit line to the material. If material is not included in the article's Creative Commons licence and your intended use is not permitted by statutory regulation or exceeds the permitted use, you will need to obtain permission directly from the copyright holder. To view a copy of this licence, visit http://creativecommons.org/licenses/by/4.0/. The Creative Commons Public Domain Dedication waiver (http://creativecommons.org/publicdomain/zero/1.0/) applies to the data made available in this article, unless otherwise stated in a credit line to the data. 


\section{Background}

Physical activity (PA) is well-known for many health benefits [1]. The association between PA and academic achievement has further been given considerable attention. The applicability of PA to improve academic achievement is promising, but findings are mixed [2, 3]. However, more than eight out of ten adolescents are insufficiently physically active and PA levels among adolescents decrease significantly [4]. Strategies to counter this negative development are essential.

Schools are considered key settings for the promotion of PA in children as they provide convenient access to the majority of young people and feature core facilities, personnel and ethos to engage children in PA [5]. Therefore, both local, regional, and national governments and international bodies have released guidelines or policies mandating structured PA in schools $[6,7]$.

A wide-ranging school reform was introduced by the Danish Government in 2014 [8]. The school reform applied to all 1095 public schools in Denmark, and the overall aim was to ensure that all children met their full learning potential [9]. As part of the school reform, a requirement for all public schools to implement an average of $45 \mathrm{~min}$ PA within the curriculum per day was included for the first time in history. The Danish school reform is one of a select few examples worldwide of a scaled-up requirement mandating daily PA to be integrated into the school curriculum. Ideally, developing guidelines or policies for schools is, among other things, focused on translating evidence into community practice [10]. However, research suggests that most schools fail to implement PA policies at scale [11]. Translating and disseminating health-related policies into a real-world context is often challenging. Various barriers have previously been identified to affect the implementation of PA programs, such as lack of time, school management buyin, and lack of facilities $[11,12]$. However, limited research has been conducted on scaled-up real-world school-based PA programs, which call for a better understanding of the complex systems of contextual factors and practical implications driving both policy development and implementation in real-world contexts [1315]. Thus, it is highly relevant to take a thorough look at the implementation of the nationwide PA requirement of the Danish school reform. The Reach, Effectiveness, Adoption, Implementation, and Maintenance framework (RE-AIM) has been deemed useful to evaluate internal and external validity of PA promotion programs, helping to provide a comprehensive evaluation $[16,17]$. In particular, the RE-AIM framework has been used to evaluate real-world programs focusing on the implementation of PA in a school context [18-20]. Using the RE-AIM framework as an evaluation tool, the objective of the current study was to explore the reach, effectiveness, adoption, implementation, and maintenance of mandatory PA within the curriculum at ten Danish schools.

\section{Methods \\ School context}

In Denmark, public (state) schools are government (tax) funded and free of charge for all children between 6 and 16 years of age and mandatory unless attending private schools or homeschooling. The majority of children (77\%) in Denmark attend public schools [8]. Most of the remaining children attend private or Danish free schools. Schools are typically organized in three tiers: prepreparatory classes (grades 0-3, 5-9 years old), intermediate classes (grades 4-6, 9-12 years old), and lower secondary classes (grades 7-9, 12-15 years old). Children attend school 30-35 h per week, of which approximately 60-75 min per day are dedicated to recess. As a mandate of the school reform, daily PA was required to be integrated within the academic curriculum - within lessons or active breaks between lessons. The PA requirement also demanded that students had at least 6090 min of physical education (PE) per week depending on age group. PE was included as part of the $45 \mathrm{~min}$ of daily PA, whereas recess was not [9]. The Government made no requirements on how to implement the mandatory PA components.

\section{Study design}

The present study is part of a larger study, the Physical Activity in Schools After the Reform (PHASAR) study, aiming to evaluate the implementation and effects of the nationwide school-based PA legislation [21]. For this sub-study, a complementary mixed-methods design [22] was used to ensure a comprehensive understanding of the school level reach, effectiveness, adoption, implementation, and maintenance of the mandatory PA components.

\section{Study population}

The ten schools included in the present study were recruited from the PHASAR study [21]. A total of 31 representative schools were included in the PHASAR study. The schools varied in geographic location, school size, municipal expenses per student, and disposable household income. School managers from eleven of the 31 schools were invited to participate in a semi-structured interview, excluding 20 schools for participation in this sub-study. From these eleven schools, ten schools that served adolescents 10-16 years old were included in the analysis. Thus, one school was further excluded, because they only served children 6-9 years old (see Fig. 1). Exclusion of children aged 6-9 years (grades 1-4) were chosen, as the PA level among the youngest children 


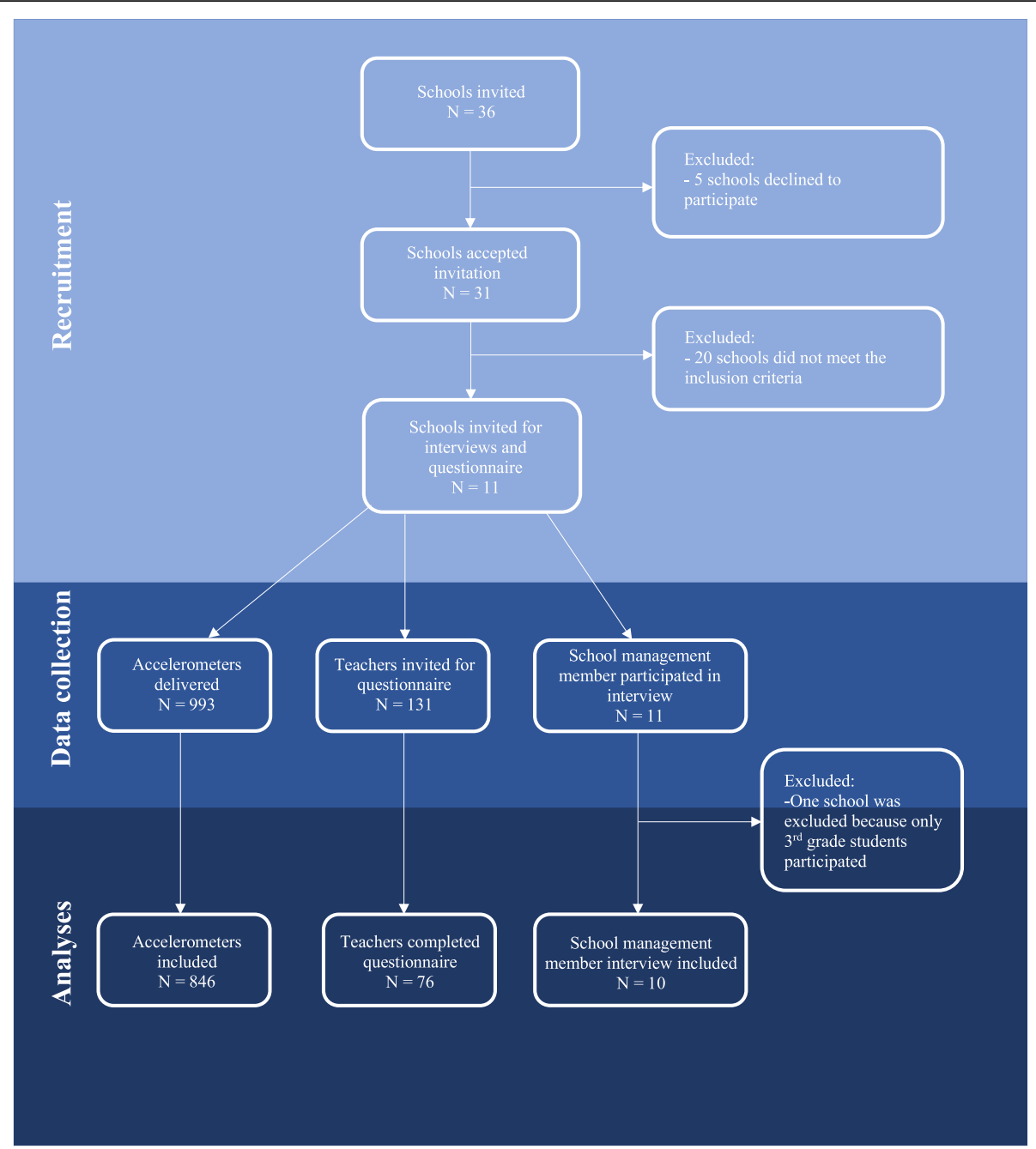

Fig. 1 Flowchart of recruitment and measures

vary a lot from the PA level of adolescents. Maximum variation was used in selecting the schools to ensure a broad representation of school contexts, including geographic location, school size, and disposable household income. Characteristics of the ten selected schools are presented in Table 1.

The study population of interest were students in grades 5-9, who were asked to wear an accelerometer; teachers, who were asked to participate in a questionnaire; and one school manager from each school to participate in a semi-structured interview. Danish, Mathematics, and English courses take up a little more than half $(53 \%)$ of the total teaching time in Danish public schools. Thus, teachers were eligible to participate in this study if they taught Danish, Mathematics, or English in one of the participating classes. The principals were recruited through purposeful sampling [23] to ensure knowledge from key respondents having insight into the implementation process of the PA requirement. The ten school managers consisted of three principals, four deputy principals, and three leading teachers with school management responsibilities.

\section{Re-aim}

The RE-AIM framework was used to guide the evaluation, as it has shown useful when evaluating real-world programs and has a specific focus on implementation of new practices in a school setting $[19,20]$. The definition, outcomes measures, and data sources of each dimension are presented below.

\section{Reach}

The reach dimension was defined as the characteristics of the ten schools selected for participation. Reach was described to ensure variation in relation to schools that were included in the present study compared to the non-participating schools $(n=21)$. School characteristics were assessed using data on geographic location, 
Table 1 Characteristics of the ten participating schools

\begin{tabular}{|c|c|c|c|c|c|}
\hline School & Geographic location & $\begin{array}{l}\text { School size } \\
\text { (number of } \\
\text { students) }\end{array}$ & $\begin{array}{l}\text { Level of } \\
\text { school }\end{array}$ & $\begin{array}{l}\text { Municipal expenses per student } \\
\text { (USD) }\end{array}$ & $\begin{array}{l}\text { Disposable household } \\
\text { (USD) }\end{array}$ \\
\hline 1 & $\begin{array}{l}\text { Region of Southern } \\
\text { Denmark }\end{array}$ & 385 & Grades 4-9 & 11,951 & 67,545 \\
\hline 2 & $\begin{array}{l}\text { Region of Southern } \\
\text { Denmark }\end{array}$ & 324 & Grades 0-6 & 11,951 & 49,789 \\
\hline 3 & $\begin{array}{l}\text { Region of Southern } \\
\text { Denmark }\end{array}$ & 609 & Grades 0-9 & 10,287 & 105,548 \\
\hline 4 & $\begin{array}{l}\text { Region of Southern } \\
\text { Denmark }\end{array}$ & 359 & Grades 0-9 & 10,287 & 68,798 \\
\hline 5 & $\begin{array}{l}\text { Region of Southern } \\
\text { Denmark }\end{array}$ & 347 & Grades 0-9 & 10,287 & 83,993 \\
\hline 6 & $\begin{array}{l}\text { Region of Southern } \\
\text { Denmark }\end{array}$ & 866 & Grades 0-9 & 11,129 & 69,559 \\
\hline 7 & $\begin{array}{l}\text { Region of Southern } \\
\text { Denmark }\end{array}$ & 764 & Grades 0-10 & 11,263 & 76,568 \\
\hline 8 & $\begin{array}{l}\text { Region of Southern } \\
\text { Denmark }\end{array}$ & 605 & Grades 0-10 & 11,052 & 85,112 \\
\hline 9 & Capital region & 904 & Grades 0-9 & 11,130 & 50,540 \\
\hline 10 & Capital region & 580 & Grades 0-10 & 11,130 & 49,367 \\
\hline
\end{tabular}

municipal expenses per student, school size, and disposable household income. School characteristics were assessed using the Danish Database of National Statistics.

\section{Effectiveness}

A more detailed effectiveness evaluation of the PHASAR study is described elsewhere [21]. In this sub-study, effectiveness was defined as the percentage of students who, on average, reached 45 min daily $P A$ within the curriculum. The effectiveness dimension further reports on average minutes of PA within the curriculum and range in minutes of daily PA across schools. The students' PA was objectively measured using accelerometers and compared across schools. In the present study, PA was defined as standing with movement, walking, and running. The definition was based on recent research, identifying sitting, standing, walking, running, and biking using accelerometers [24].

\section{Adoption}

Although all public schools in Denmark were required to implement mandatory PA within the curriculum, there was no guarantee that school managers and teachers would and/or could adopt this. The adoption dimension reports on the schools' commitment to the mandatory PA within the curriculum and factors influencing adoption. Adoption rates were measured through a teacher questionnaire, whereas factors central for adoption were measured through semi-structured interviews with school managers.

\section{Implementation}

Implementation was defined as schools' PA initiatives (e.g., structuring PA within schedules) and reports on the extent of PA delivered within the curriculum and schools' process of implementing the mandatory PA within the curriculum. Furthermore, the dimension reports on factors influencing implementation of the mandatory PA within the curriculum. The extent of PA delivered within the curriculum was measured through a teacher questionnaire and factors central for implementation were measured through semi-structured interviews with school managers.

\section{Maintenance}

During the data collection, conducted 3-4 years after the introduction of the reform, most schools indicated that implementation had started, but had not been fully completed. Thus, the maintenance dimension reports on the extent to which schools have considered how to ensure maintenance. Maintenance was measured through semistructured interviews within school managers.

\section{Data sources}

Four data sources were collected: national statistics, accelerometers, a questionnaire aimed at teachers, and semi-structured interviews with school managers. Figure 2 presents a timeline of when each data source was collected. 


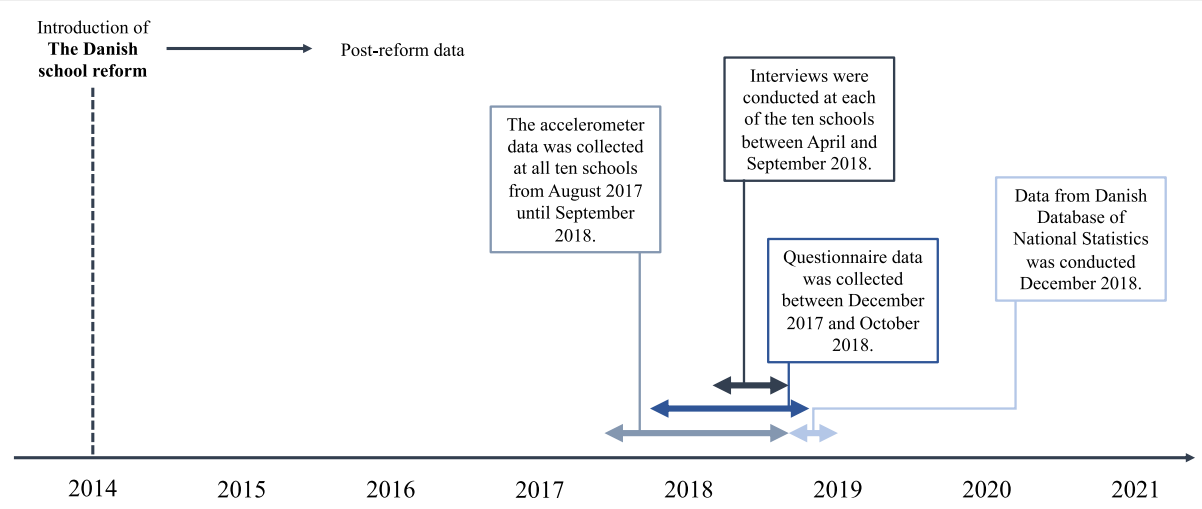

Fig. 2 Timeline for data collection

\section{Danish database of national statistics}

The Danish Database of National Statistics was used to gather information on municipal expenses per student, school size, and disposable household income. The information was gathered in December 2018.

\section{Accelerometers}

The Axivity AX3 data logger was used to assess objectively measured PA. Students were invited to wear an accelerometer for seven consecutive days. Mounted in a belt placed directly against the skin around the subject's right front thigh, the accelerometer provided an opportunity to calculate the duration spent on specific activity types. In this method, the acceleration is utilized in relation to the orientation of the subject's thigh, which enabled us to distinguish very accurately between, for example, sitting and standing position. The accelerometer data was collected from August 2017 until September 2018. Standardized testing protocols were made to ensure data quality, and trained research assistants collected all data. Prior to the initiation of the study, a pilot study was conducted to optimize all study procedures. Accelerometry-based PA measures were analyzed for the curricular time during the school day (excluding recess).

\section{Questionnaire}

A questionnaire was designed to measure how often teachers employed PA within the curriculum and their attitudes towards the requirement (e.g., how often do you implement PA within the curricular teaching?; to what extent do you agree that PA could advance student learning?).

Several steps were taken to heighten the content validity of the questionnaire. Initially, the questionnaire was developed by two authors of the present study. Subsequently, the questionnaire was tested and discussed by several members of the PHASAR research group before pilot testing. The online procedure and the questionnaire were pilot tested with a group of teachers not included in the study to ensure face validity.

The questionnaire was designed and collected through the worldwide system Research Electronic Data Capture (RedCap). The use of electronic questionnaires made it possible to activate additional questions on specific answers, thereby ensuring that participants did not receive irrelevant questions. At the end of most questions, teachers were given the opportunity to add additional comments. The questionnaire was administered electronically, and the participating teachers were emailed a hyperlink to the questionnaire. Reminders were e-mailed to participants who did not respond (three times with 1 week between each reminder). Questionnaire data was collected between December 2017 and October 2018.

\section{Semi-structured interviews}

Ten interviews with school managers were conducted (one from each school). The interview guide was based on the Practical, Robust Implementation and Sustainability Model (PRISM) [25]. In particular, the interview focused on the adoption (e.g., how does the requirement fit within the existing school structure?), implementation (e.g., how do you organize your PA initiatives?), and maintenance dimensions (e.g., have you considered how to ensure maintenance of your initiatives?).

Interviews were conducted during a one-day visit to each of the ten schools between April and September 2018. All interviews were conducted one-on-one by the lead author and lasted between 25 and $60 \mathrm{~min}$. Verbal consent was obtained from each participant to audio record the interview.

\section{Data analysis}

\section{Quantitative data analysis}

STATA 16 (College Station, TX) was used to handle the quantitative data. Descriptive statistics were produced for the accelerometers' data in order to gather information on the percentage of students who on average 
reached $45 \mathrm{~min}$ of daily PA. Students with non-wear or with less than one valid school day were excluded from the analysis. The activity types were analyzed in twosecond intervals [24]. On this basis, PA was defined as the sum of the activity types stand with movement, walking, and running. Thus, sitting and standing were excluded during data processing.

Due to the paucity of responses in the questionnaire $(n=76)$, using a Likert scale became meaningless. Thus, 5-point Likert scale values were collapsed into two categories: "agree" and "disagree", and 7-point Likert scale values were collapsed into four categories: "every day", "weekly", "monthly", and "yearly or newer". Descriptive statistics were produced on questionnaire data as well as data from the Danish Database of National Statistics. To analyze the reach component, two-sample t-tests were used to investigate the potential difference between participating and non-participating schools on municipal expenses per student, school size, and disposable household income. The level of significance was set at $p<.05$.

\section{Qualitative data analysis}

The interviews were transcribed by the lead author to ensure consistency. All interviews were transcribed verbatim directly into NVivo. Data was analyzed using a three-step qualitative thematic analysis [26]. First, all interviews were read through by two authors (SK and CSP) to ensure data familiarization. Coding was then conducted by both authors separately by marking all phrases concerning adoption, implementation, and maintenance, respectively. Secondly, all codes within the adoption, implementation, and maintenance dimension were read through. An open coding was then conducted, letting the data speak for itself [27]. As a result, themes were developed within the adoption, implementation, and maintenance dimension, respectively. Lastly, the findings were discussed among the two authors. Any discrepancies were resolved by consensus between the two authors [28].

\section{Ethical considerations}

Prior to the data collection, students and their parents or guardians received information about the study. Consent took form as an oral and written informed passive consent from parents or guardians and students, entailing that all students were included in the study unless parents, guardians or the student decided to withdraw, which they were able to do at any time. Written consent was obtained from all principals, deputy principals, and leading teachers participating in the semi-structured interview. They were informed that they could withdraw from the study at any time. Schools and participants were anonymized by giving the schools numbers and naming participants by profession. The study was notified and approved by the Danish Data Protection Agency (2015-57-0008), who also gave legal advice and confirmed the legal basis of the informed passive consent.

\section{Results}

Reach

Denmark consists of five regions and despite the criteria of variation in geographical location in the school selection process, eight schools were located in the region of Southern Denmark and two schools were located in the Capital region. Thus, schools in the region of Southern Denmark were overrepresented in the present study. There was no significant difference in municipal expenses per student $(p>0.98)$, school size $(p>0.15)$, or disposable household income $(p>0.57)$ between participating and non-participating schools.

\section{Effectiveness}

A total of 846 students were included in the analysis: 475 girls and 371 boys. On average, almost half of the participating students (45.2\%) were active at least $45 \mathrm{~min}$ daily within the curriculum and thus reached the reform's PA requirement. Large differences were, however, observed between schools. At the school with the lowest effectiveness (school \#3), only $4.5 \%$ of students reached 45 min daily PA within the curriculum, while $82.6 \%$ of students at the school with the highest effectiveness (school \#2) reached the requirement. Students were, on average, active $48.5 \mathrm{~min}$ daily within the curriculum. Large differences were seen between students, ranging from $5.2 \mathrm{~min}$ to $115.4 \mathrm{~min}$ of daily PA within the curriculum. An overview of accelerometer results is presented in Table 2.

\section{Adoption}

Results from the teacher questionnaire $(\mathrm{n}=76)$ revealed a general commitment to the mandatory PA component with $94.3 \%$ of all participating teachers believing that daily PA within the curriculum was important. In addition, $90.3 \%$ agreed that PA could advance student learning and $69.0 \%$ generally acknowledged that including PA in the curriculum activities had positive impacts.

From the interviews, four key-findings for adoption of the mandatory PA components were found: teacher and school management interest in PA, school management support, competencies development, and shared decision-making. All ten school managers interviewed found the mandatory PA within the curriculum meaningful, and at four schools (school \#1, \#2, \#8, and \#9) PA was already a central part of school culture before the 2014 reform. During interviews, however, school managers generally stated that some teachers were skeptical about the mandatory PA within the curriculum: 
Table 2 Accelerometers results on school level

\begin{tabular}{|c|c|c|c|c|c|c|c|c|c|c|c|}
\hline School & Total & 1 & 2 & 3 & 4 & 5 & 6 & 7 & 8 & 9 & 10 \\
\hline Grade & $5-9$ & $5-6$ & $5-6$ & 9 & 9 & 9 & $5-8$ & $5-8$ & $5-8$ & $6-8$ & $5-8$ \\
\hline $\begin{array}{l}\% \text { students reaching } 45 \mathrm{~min} \text {. Daily PA within } \\
\text { the curriculum }\end{array}$ & 45.2 & 80.8 & 82.6 & 4.5 & 35.3 & 33.3 & 32.3 & 40.7 & 73.6 & 30.4 & 38.8 \\
\hline $\begin{array}{l}\text { Average daily PA within the curriculum } \\
\text { (minutes) }\end{array}$ & 48.5 & 56.1 & 60.1 & 32.3 & 38.5 & 39.2 & 40.7 & 41.9 & 57.3 & 42.8 & 42.5 \\
\hline $\begin{array}{l}\text { Range (min/max) of PA within the curriculum } \\
\text { (minutes) }\end{array}$ & $\begin{array}{l}5.2- \\
115.4\end{array}$ & $\begin{array}{l}15.3- \\
84.8\end{array}$ & $\begin{array}{l}28.4- \\
102.5\end{array}$ & $\begin{array}{l}10.7- \\
45.3\end{array}$ & $\begin{array}{l}11.3- \\
68.0\end{array}$ & $\begin{array}{l}16.7- \\
56.6\end{array}$ & $\begin{array}{l}5.2- \\
76.0\end{array}$ & $\begin{array}{l}11.5- \\
103.1\end{array}$ & $\begin{array}{l}13.7- \\
115.4\end{array}$ & $\begin{array}{l}22.8- \\
95.9\end{array}$ & $\begin{array}{l}18.7- \\
76.7\end{array}$ \\
\hline
\end{tabular}

"I think it depends on your interests. There are some [teachers, Ed.] who absolutely do not believe that PA does any good. That it's rather a disturbing element". (Leading teacher, school \#3)

The individual teacher's interest in PA seemed crucial for commitment to the mandatory PA within the curriculum. Also, managerial support was important in order to take responsibility for developing a school culture supporting the delivery of PA within the curriculum.

"It's about making them [teachers, Ed.] think it's a good idea. And to do so, I need to be dedicated to it. And I need to take responsibility for the process in order to make it grow”. (Deputy principal, school \#6)

Furthermore, most school managers had experienced teachers who, from the outset, were poorly prepared for handling PA within the curriculum, challenging the adoption of the PA requirement. At five of the included schools (school \#1, \#2, \#3, \#4, and \#9), it was therefore prioritized that all teachers participated in either a course or a workshop to strengthen their skills in how to include PA within the curriculum. The interviews showed that especially workshops or courses conducted by internal coordinators were useful for school adoption of the requirement, allowing teachers to continuously develop their competencies through ongoing follow-up workshops or courses.

"It is our teachers who planned the pedagogical day, which means that after these workshops teachers know from whom they can be aided or take inspiration (...) Instead of hiring an external course organizer, who will leave afterwards along with the information. This way the information stays at the school, so that we continuously can get hold of it, which motivates teachers to take active part in it". (Head of school \#3)

Delivering PA within the curriculum required that some teachers renewed learning formats - challenging their professional identity and calling for new or, at least, adjusted approaches to teaching. Some teachers believed a heightened focus on PA threatened the academic standard of their teaching:

"Renewing your teaching is a really, really huge challenge. (...) It's difficult because it's a change of so many habits and working methods, which you [teachers, Ed.] believe students will learn a lot from". (Principal, school \#3)

\section{Implementation}

Results from the teacher questionnaire showed that 9.5\% of the participating teachers delivered PA within the curriculum on a daily basis, whereas $53.4 \%$ delivered PA within the curriculum on a weekly basis. Results showed a general consistency between schools. From the interviews, two key findings for implementation of PA within the curriculum were found: scheduling PA within schedules and collaborations with external parties. Six schools had scheduled PA within the school day to ensure that PA was delivered on fixed timepoints throughout the week. At three of six schools (school \#4, \#7, and \#8) PA was scheduled as short daily lessons of 15-30 min dedicated to PA. The other three schools (school \#1, \#2, and \#9) had integrated more physical education (PE) within schedules, having four or six weekly lessons of PE compared to the norm of two lessons. Scheduling PA/PE was done to support teachers for whom PA did not naturally lend itself to the curriculum: "I think that planning PA into schedules helps. Well, it helps to know that if you forget all about $P A$, you at least have a lesson dedicated to $P A$ ". (Principal, school \#4).

Five schools (school \#1, \#2, \#7, \#8, and \#9) developed principles, meeting structures, or conducted workshops in order to achieve motivation for delivering PA within the curriculum, intending to heighten school staff commitment. These initiatives were all developed through shared decision-making between school managers and teachers, ensuring that the school developed a shared vision for how to deliver PA within the curriculum: "I think it's about developing a culture ... a shared vision ... and a common mindset about the importance of PA". (Deputy principal, school \#7). 
Seven schools collaborated with external parties as part of their PA implementation. Two schools (school \#2 and \#6) collaborated with the municipality or a national sports organization, participating in PA promotion projects. Five schools (school \#2, \#4, \#6, \#8, and \#9) had established collaborations with local sports associations, inviting sports associations to organize workshops for the students or take part in PE lessons. All school managers collaborating with external parties found it beneficial in order to implement PA within the curriculum:

"We have established a collaboration with an athletics club and a cycling club. (... ) We have some facilities and opportunities here at the school, but the collaborations are also about being able to thrive on associations with other facilities and opportunities than what we have here”. (Principal, school \#4)

Thus, collaboration with external parties helped schools accomplishing the mandatory PA component, putting facilities and instructors at disposal.

\section{Maintenance}

From the interviews, four key findings for maintenance of PA within the curriculum were found: internal coordinators, motivated school staff, school management priority, and municipal support. Six school managers (school \#2, \#3, \#4, \#5, \#9, and \#10) stated that internal coordination was essential for maintenance. The coordinators were, among other things, important for sharing hands-on knowledge and inspiring teachers to deliver PA in new and different ways:

"In order to continue delivering $P A$ within the curriculum, we will continue having $P A$ coordinators at all bases [year groups, Ed.]. And if one of those leave another one will take its place”. (Deputy principal, School \#9)

Having teachers especially motivated for PA was another important factor for maintenance. Two schools (school \#2 and \#9) even stated that, when hiring, they searched for teachers interested in PA. In order to ensure maintenance, several principals also stated that PA needed to be a school management priority, allocating resources for PA education and materials, and leading a common strategy for delivering PA within the curriculum: "I think there are things that are essential for sustainability. One such thing is that it has to be a management priority". (Deputy principal, School \#2).

Interviews showed, however, that school managers felt a lack of support from the municipality to maintain PA initiatives within the curriculum. Local politics were perceived to change and evolve continuously, and schools were obligated to support policy developments on a huge number of areas - PA being just one of these. At times, the sheer volume of new initiatives made it difficult for school managers to dedicate adequate resources for one area like PA:

"In our municipality, we are required to produce something called 'focus areas'. I think I am about to produce the sixth focus area within one and a half year. And if you continue to introduce a new focus area every two or three months, you will lose sight of the focus area you were using 9 months ago" (Principal, school \#3).

\section{Discussion}

The objective of the current study was to explore the reach, effectiveness, adoption, implementation, and maintenance of mandatory PA within the curriculum at ten Danish schools. The RE-AIM evaluation tool identified central factors discussed further below.

\section{Commitment and school culture}

Generally, school managers and teachers in the sample were interested in the PA requirement, finding it meaningful, believing that PA within the curriculum was important, and that PA could advance student learning. However, these findings do not necessarily reflect teachers' willingness to actually implement PA within the curriculum. For instance, at the two schools with the lowest percentage of students reaching the requirement, all teachers responding to the questionnaire agreed on the aforementioned factors. Thus, the attitude toward PA might be removed from the actual behavior at these schools. Despite this finding, interest in PA has been reflected by others as an advantage for the implementation process, since it ensures that both teachers and school managers already having an awareness of the importance of the requirement $[12,13,15]$.

Forty percent of the schools in the sample had already adopted PA as a central part of the school culture prior to introduction of the school reform. Three of those schools had the highest percentage of students reaching the PA requirement measured by accelerometry. The extent to which the requirement fits within an organization's mission, priorities, and values has previously been pointed out as impacting the commitment towards realizing the implementation $[12,13,29,30]$. A study by Webster et al. (2020) found, however, that most schools are largely unprepared to implement multicomponent approaches (e.g., the Danish school reform), inhibiting schools from adopting the program. Thus, existing school culture might be an important factor for the degree of implementation. 


\section{Organisation of PA within the curriculum}

Almost two-thirds of the teachers reported delivering PA within the curriculum weekly (53.4\%), but the number reporting daily delivery, in keeping with the requirement, was extremely low; less than $10 \%$. In concert with this, less than half of the students achieved $45 \mathrm{~min}$ of daily PA. Thus, the requirement was initiated to some degree, but was far from fully implemented.

Two key suggestions related to implementation of the mandatory PA within the curriculum were highlighted by the school managers: scheduling PA within school schedules and collaborations with external parties. Introducing a mandatory PA requirement strongly urges school staff to adhere to the requirement. At the same time, there has been an increasing pressure placed on teachers to improve academic performance, and some teachers perceive time spent on academic work to be more beneficial compared with time spent on PA [31]. Prioritizing becomes even more strained. Thus, planning PA/PE within school schedules helps ensure that students achieve the mandatory amount of PA within the curriculum, while teachers can focusing on the content of the academic teaching in the remaining lessons. Sixty percent of the schools in the sample scheduled their PA in the daily schedule. At three of those schools, more than $70 \%$ of the students achieved the requirement. Two of these schools had tripled the amount of weekly PE and the last one had scheduled $30 \mathrm{~min}$ dedicated to PA daily. At the remaining three schools, $30-40 \%$ of students reached the requirement. For some schools, scheduling PA/PE seemed beneficial in order to accomplish the daily mandatory PA within the curriculum. This is also reflected in previous studies, highlighting scheduling of PA as a facilitator to implementation of PA policies in schools [32]. Moreover, well-defined program components and an extensive teacher manual to support implementation has also been regarded as important for program implementation [12, 33].

Another way to help schools to accomplish the PA requirement could be through collaborations with external parties (e.g., local or national sports clubs or consultant or instructor from the municipality). This is in line with the Comprehensive School Physical Activity Program (CSPAP) Model, including family and community engagement as one part of the model. This model endorses engagement of families and the community in school events to increase students PA levels [34]. This is also reflected in other studies, showing that cooperation and collaboration among local agencies (e.g., partnerships, networking) are beneficial, bringing different perspectives, skills, and resources to bear on the implementation [13, 35, 36]. A study by de Meij et al. (2013) further supports collaborating with external parties, stating that involvement and support of experts in sports, health, and education is a facilitating factor for implementation at the user level.

\section{Motivation of school staff}

Most school managers in the sample had experienced teachers who were poorly prepared for handling PA within the curriculum, highlighting the importance of competencies development. While often defined as development of skills necessary for implementation, competencies development is equally about having a fundamental mindset about how to handle the implementation [30, 35, 37]. In addition, Durlak and Dupre (2008) state that development of competencies is also about developing motivation and self-efficacy. Such qualities affect future performance [13]. Thus, motivated school staff is an important factor for the implementation process and has been identified to affect both adoption, implementation, and maintenance [12, 38]. This is in line with Nielsen et al. (2018), highlighting the need for teachers to be trained to develop the skills and self-efficacy needed to feel motivated and dedicated to the implementation. However, despite receiving training and education, many teachers have relatively little knowledge and skills in relation to implementation of PA [39]. Moreover, despite having received training and education, some teachers may still opt not to accommodate the implementation because they are busy with other duties within an educational system where academic performance is the number one priority [34].

In order to ensure motivated school staff, internal coordinators were highlighted as favorable agents to include in the implementation process, taking care of workshops, competencies development, and ongoing training for teachers. One of the five schools, which stated that internal coordinators were essential for maintenance, was the school with highest effectiveness. This school had a team of coordinators, mostly consisting of $\mathrm{PE}$ teachers, responsible for making a common thread for integration of PA, ensuring that all teachers, independent of PA competencies, were able to deliver qualified PA within the curriculum. At the four other schools that supported the use of internal coordinators, between 30 and $38 \%$ of the students were active during curricular time. However, the schools in question were just embarking on the process of organizing internal coordinators. Appointing internal coordinators or program champions has been highlighted as being advantageous to ensure a successful implementation process [13, 29, 40]. Program champions, particularly senior staff within an organization and who are respected by the other staff, can do much to help orchestrate a program through the entire diffusion process from adoption to 
maintenance [13]. This could be a school manager, but it could also be PE teachers, classroom teachers, administrators, or others who are well-suited to lead the implementation [34, 41].

\section{School management support}

The support of school management was shown to be vitally important for developing a school culture prioritizing the delivery of PA within the curriculum. This is also highlighted by others, reporting that school management support is a clear enhancement in securing motivation to PA programs $[12,13,33]$. Moreover, in a schoolbased mental health program, Kam et al. (2003) showed a significant association between school management support and teachers' fidelity of the implementation on student outcomes. Students improved significantly on all outcomes when both school management support and teachers' fidelity of the implementation were high. However, this research found several negative changes when school management support was low. This underlines the importance of school management support of the program [42].

School managers in the sample had experienced teachers that were skeptical towards the mandatory PA components, which could be due to the additional workload following the requirement. A study on the implementation of the CSPAP found that many schools view the addition of PA program as an extra responsibility in an already over-loaded school agenda [34]. Other studies show that when introducing new programs, teachers are concerned about additional workloads which challenge them to prioritize possibilities and obligations [15, 43, 44]. Our study highlights the importance of shared decision-making, as teacher involvement reportedly heightened commitment to the program. Involvement of teachers in decision-making processes (e.g., development of a PA implementation strategy) has previously been highlighted as a cornerstone in implementation of PA programs, uniting organizational members regarding the value and purpose of the program [12, 45]. This further clarifies the importance of school management support, taking responsibility for leading the implementation process through teacher involvement and dialog in order to ensure motivation and ownership for the implementation.

Our research suggests that school management support of PA implementation would be a central factor in maintenance. This is in line with previous research, highlighting that school management support is crucial for creating coherence and prioritizing in situations where consensus about what exactly should be done many times is only partial $[13,35,38,46]$. A review by Cassar et al. (2019), among others, also found that active involvement of school managers, supporting and prioritizing the PA program, was a key determinant for both implementation and maintenance [12, 47-49].

\section{Municipal support}

Municipal support was addressed as an important factor for maintenance. However, some schools felt a lack of municipal support during the implementation of the PA requirement. One of those schools was the school with the lowest percentage of students reaching the PA requirement.

Schools and the educational system are busy with the core business of teaching and learning. This premise affects specific agendas on, for instance, increasing the volume of curriculum-based PA [50]. The need for continued municipal support is frequently highlighted stressing that allocation of resources to schools (e.g., time for schools to develop an PA strategy or support regarding facilities) is needed [13, 51, 52]. Moreover, a study by Skovgaard \& Johansen (2020) highlighted the importance of managers (both school and district managers), employees, and other core stakeholders developing a shared strategy for the area and setting ambitious goals that can realistically be achieved. Such a strategy could help both schools and municipalities to reach a common understanding of the implementation process - that it takes time and that schools are not able to implement new strategies every two months.

The two schools with the highest percentage of students reaching the PA requirement were located in the same municipality. All schools in this municipality were financially supported by the municipality if they chose to become part of their local PA program, tripling the amount of weekly PE. This case is an example of a successful implementation process with active involvement of both schools and municipalities in developing a shared strategy [19].

\section{Methodological considerations}

A strength of this study was the use of multiple data sources including accelerometers, a questionnaire, and interviews, as it provided a more comprehensive understanding of the RE-AIM dimensions and strengthened the external validity, credibility, and transferability of the study $[22,53]$. That being said, we do recognize that this study has some limitations. Generally, eight of the included schools were located in the region of Southern Denmark and two schools were located in the capital region. Inclusion of schools from other regions would have been beneficial, ensuring greater national representativeness. Due to the design of the PHASAR study, this was not a possibility, though [21].

Another general limitation was the inclusion of students from different grades, which made it difficult to compare schools. Consequently, the results indicate that 
students in lower grades are more active than students in upper grades. Ideally, students from the same grades should have been included at all of the participating schools. Unfortunately, this was not possible due to the PHASAR study design. Although some steps were taken to achieve a comparable sample, the age factor still seemed to be of considerable importance to student PA levels.

Another limitation is that recall bias may have emerged, since the interviews were conducted three to four years after introduction of the school reform. Finally, it is important to acknowledge that the present study only represents teachers' views through the questionnaire. The teachers were unfortunately not able to take part in the interviews due to limited time allocated for taking part in the study.

\section{Conclusions}

Using the RE-AIM framework, this study explores the implementation of a nationwide requirement mandating integration of daily PA into Danish public school curricular time. Notably, implementation varied across schools and could be described as partially implemented after four years. Our study showed the importance of school management in monitoring, prioritizing, and supporting the implementation process and taking the lead on establishing a school culture centered around PA. We also showed the importance of teacher involvement, ensuring motivation and ownership for the implementation.

In terms of implementation, the benefit of appointing an internal coordinator or coordination teams to provide teacher competence development; inspirational materials easy for teachers to use within the curriculum; and ongoing training were highlighted. Finally, it seems beneficial for municipalities, school managers, teachers, and other stakeholders to develop a shared strategy for the implementation process and to set ambitious goals, which are realistic to achieve. Thus, targeting the implementation at multiple levels within the educational system, such as the capacity of school managers to lead the process, teacher buy-in by active involvement, internal coordinators, and municipal support, might increase the probability for successful implementation of scaled-up real-world programs.

\section{Abbreviations \\ PA: physical activity; PE: physical education; RE-AIM: Reach, Effectiveness, Adoption, Implementation and Maintenance; PHASAR: Physical Activity in Schools After the Reform; Redcap: Research Electronic Data Capture; PRISM: Practical, Robust Implementation and Sustainability Model}

\section{Acknowledgements}

We are grateful to the participating schools, students, teachers, school managers and school administrations for their kind participation in the study. We also acknowledge professional work done by the internal language service at University of Southern Denmark for carefully going through the manuscript.

\section{Authors' contributions \\ SK, CSP, JT and TS participated in the development of the study design. NHP and SK participated in the data collection and NHP processed the accelerometer data. CSP and SK conducted the coding and the analysis of the qualitative data. SK initiated this paper and wrote the draft. All of the authors contributed to the writing of the manuscript and critically reviewed its content. All of the authors approved the final version before submission.}

\section{Funding}

The PHASAR project (ID 115606) is funded by the Danish Foundation

TrygFonden (http://trygfonden.dk/english)

\section{Availability of data and materials}

The dataset supporting the conclusions of this article are available at the time of publication upon application to the PHASAR Steering Committee (ktlarsen@health.sdu.dk). If approved by the Steering Committee and the Danish Data Protection Agency, data will be available.

\section{Declarations}

Ethics approval and consent to participate

Consent took form as an oral and written informed passive consent from parents or guardians and students, entailing that all students were included in the study unless parents, guardians or the student decided to withdraw, which they were able to do at any time. Written consent was obtained from all principals, deputy principals, and leading teachers participating in the semi-structured interview. The need for ethical approval was waived by the Regional Scientific Ethical Committee (The Region of Southern Denmark, Regionshuset, Damhaven 12, DK-7100 Vejle), since no intervention was provided by the research team and the study did not contain any human biological material (cf. the guidelines from the National Scientific Ethical

Committee). The project was notified and approved by the Danish Data Protection Agency (2015-57-0008), who also provided legal advice and confirmed the legal basis of the informed passive consent. All data is stored and treated in accordance with Danish law for protection and the General Data Protection Regulation.

\section{Consent for publication}

Consent for publication was obtained from all subjects.

\section{Competing interests}

The authors declare no competing interests.

\section{Author details}

${ }^{1}$ Research Unit for Active Living, Department of Sports Science and Clinical Biomechanics, University of Southern Denmark, Campusvej 55, 5230 Odense M, Denmark. ${ }^{2}$ Research and Implementation Centre for Human Movement and Learning, Department of Sports Science and Clinical Biomechanics, University of Southern Denmark, Campusvej 55, 5230 Odense M, Denmark. ${ }^{3}$ Centre of Research in Childhood Health, Department of Sports Science and Clinical Biomechanics, University of Southern Denmark, Campusvej, 55 Odense M, Denmark. ${ }^{4}$ Research Unit for Exercise Epidemiology, Department of Sports Science and Clinical Biomechanics, University of Southern Denmark, Campusvej, 55 Odense M, Denmark.

Received: 4 February 2021 Accepted: 25 October 2021

Published online: 11 November 2021

\section{References}

1. Janssen I, LeBlanc AG. Systematic review of the health benefits of physical activity and fitness in school-aged children and youth. Int J Behav Nutr Phys Act. 2010 May;7(1):40. https://doi.org/10.1186/1479-5868-7-40.

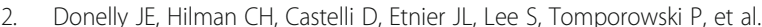
Physical activity, fitness, cognitive function, and academic achievement in children: a systematic review. Med Sci Sports Exerc. 2016 Jun;48(6):1197222. https://doi.org/10.1249/MSS.0000000000000901. 
3. Barbosa A, Whiting S, Simmonds P, Moreno RS, Mendes R, Breda J. Physical activity and academic achievement: an umbrella review. Int J Environ Res Public Health. 2020;17(16):5972. https://doi.org/10.3390/ijerph17165972.

4. Guthold R, Stevens GA, Riley LM, Bull FC. Global trends in insufficient physical activity among adolescents: a pooled analysis of 298 populationbased surveys with 1.6 million participants. Lancet Child \& Adolesc Health. 2020 Jan;4:23-35. https://doi.org/10.1016/S2352-4642(19)30323-2.

5. Dobbins M, Husson H, DeCorby K, LaRocca RL. School-based physical activity programs for promoting physical activity and fitness in children and adolescents aged 6 to 18. Cochrane Database Syst Rev. 2013 Feb;2013(2): CD007651. https://doi.org/10.1002/14651858.CD007651.pub2.

6. Allison KR, Vu-Nguyen K, Ng B, Schoueri-Mychasiw N, Dwyer JJM, Manson H, et al. Evaluation of daily physical activity (DPA) policy implementation in Ontario: surveys of elementary school administrators and teachers. BMC Public Health. 2016 Aug 8;16(1):746. https://doi.org/10.1186/s12889-01 6-3423-0.

7. Chesham RA, Booth JN, Sweeney EL, Ryde GC, Gorely T, Brooks NE, et al. The daily mile makes primary school children more active, less sedentary and improves their fitness and body composition: a quasi-experimental pilot study. BMC medicine. 2018 may;16:64. 2018;16(1):64. https://doi.org/1 0.1186/s12916-018-1049-z.

8. Ministry of Education. Antal grundskoler. 2020 Nov [cited 2020 Nov 20]. Available from https://www.uvm.dk/statistik/grundskolen/personale-ogskoler/antal-grundskoler

9. Ministry of Education. Bekendtgørelse af lov om folkeskolen. LBK nr. 1510 , §15. 2019 Aug [cited 2020 Nov 20]. Available from: https://www.retsinforma tion.dk/eli/lta/2019/823

10. Caperchione CM, Duncan M, Kolt GS, Vandelanotte C, Rosenkranz RR, Maeder A, et al. Examining an Australian physical activity and nutrition intervention using RE-AIM. Health Promot Int. 2016 Jun;31(2):450-8. https:// doi.org/10.1093/heapro/dav005.

11. Nathan N, Elton B, Babic M, McCarthy N, Sutherland R, Presseau J, et al. Barriers and facilitators to the implementation of physical activity policies in schools: a systematic review. Prev Med. 2018 Feb;107:45-53. https://doi. org/10.1016/j.ypmed.2017.11.012.

12. van Nassau F, Singh AS, Broekhuizen D, van Mechelen W, Brug J, Chinapaw MJ. Barriers and facilitators to the nationwide dissemination of the Dutch school-based obesity prevention programme DOiT. Eur Public Health. 2016 Aug;26(4):611-6. https://doi.org/10.1093/eurpub/ckv251.

13. Durlak JA, DuPre EP. Implementation matters: a review of research on the influence of implementation on program outcomes and the factors affecting implementation. Am J Community Psychol. 2008 Jun;41(3-4):32750. https://doi.org/10.1007/s10464-008-9165-0.

14. Glasgow RE, Emmons KM. How can we increase translation of research into practice? Types of evidence needed. Annu Rev Public Health. 2007;28(1): 413-33. https://doi.org/10.1146/annurev.publhealth.28.021406.144145.

15. Naylor P-J, Nettlefold L, Race D, Hoy C, Ashe MC, Higgins JW, et al. Implementation of school based physical activity interventions: a systematic review. Prev Med. 2015 Mar;72:95-115. https://doi.org/10.1016/j.ypmed.2 014.12 .034$.

16. Glasgow RE, Lichtenstein E, Marcus A. Why Don't we see more translation of health promotion research to practice? Rethinking the efficacy-toeffectiveness transition. Am J Public Health. 2003 Aug;93(8):1261-7. https:// doi.org/10.2105/ajph.93.8.1261.

17. Glasgow RE, Vogt TM, Boles SM. Evaluating the public health impact of health promotion interventions: the RE-AIM framework. Am J Public Health. 1999 Sep;89(9):1322-7. https://doi.org/10.2105/ajph.89.9.1322.

18. Cassar S, Salmon J, Timperio A, Naylor P-J, van Nassau F, Ayala AMC, et al. Adoption, implementation and sustainability of school-based physical activity and sedentary behaviour interventions in real-world setting: a systematic review. Int J Behav Nutr Phys Act. 2019 Dec;16(1):120. https://doi. org/10.1186/s12966-019-0876-4

19. Nielsen JV, Skovgaard T, Bredahl TVG, Bugge A, Wedderkopp N, Klakk H. Using the RE-AIM framework to evaluate a school-based municipal programme tripling time spent on PE. Eval Program Plann. 2018 Oct;70:111. https://doi.org/10.1016/j.evalprogplan.2018.05.005.

20. Smedegaard S, Brondeel R, Christiansen LB, Skovgaard T. What happened in the 'move for well-being in school': a process evaluation of a cluster randomized physical activity intervention using the RE-AIM framework. Int J Behav Nutr Phys Act. 2017 Nov;14(1):159. https://doi.org/10.1186/s12966-01 7-0614-8.
21. Pedersen NH, Koch S, Larsen KT, Kristensen PL, Troelsen J, Møller NC, et al. Protocol for evaluating the impact of a national school policy on physical activity levels in Danish children and adolescents: the PHASAR study - a natural experiment. BMC Public Health. 2018 Nov;18(1):1245. https://doi. org/10.1186/s12889-018-6144-8.

22. Greene JC. Mixed methods in social inquiry. San Francisco, CA: Jossey-Bass; 2007.

23. Kelly SE. Qualitative techniques and styles. In I. Bourgeault, R. Dingwall, \& R. d. Vries, editors. The SAGE handbook of qualitative methods in health research. London: Publishing; 2019. p. 307-326, Qualitative Interviewing Techniques and Styles, DOl: https://doi.org/10.4135/9781446268247.n17.

24. Brønd JC, Grøntved A, Andersen LB, Arvidsson D, Olesen LG. Simple method for the objective activity type assessment with preschoolers, children and adolescents. Children. 2020 Jul;7(72). https://doi.org/10.3390/ children7070072.

25. Feldstein AC, Glasgow RE. A practical, robust implementation and sustainability model (PRISM) for integrating research findings into practice. Jt Comm J Qual Patient Saf. 2008 Apr;34(4):228-43. https://doi.org/10.1016/ s1553-7250(08)34030-6.

26. Maxwell JA, Chmiel M. Qualitative content analysis. In: Flick U, editor. The SAGE handbook of qualitative data analysis. London: Publishing; 2014. p. 21-34. https://doi.org/10.4135/9781446282243.n2.

27. Atieno OP. An analysis of the strengths and limitation of qualitative and quantitative research paradigms. Problems of Education in the 21st Century. 2009;13:13-8.

28. Barbour RS. Quality of data analysis. In. U. Flick, editors. The SAGE handbook of qualitative data analysis. London: SAGE Publications Ltd.; 2014. p. 496509.

29. Chalkley AE, Routen AC, Harris JP, Clae LA, Gorely T, Sherar LB. A retrospective qualitative evaluation of barriers and facilitators to the implementation of a school-based running programme. BMC Public Health. 2018 Oct;18(1):1189. https://doi.org/10.1186/s12889-018-6078-1.

30. Stith S, Pruitt I, Dees J, Fronce M, Green N, Som A, et al. Implementing community-based prevention programming: a review of the literature. J Prim Prev. 2006 Nov;27(6):599-617. https://doi.org/10.1007/s10935-006.0062.8.

31. Owen KB, Parker PD, van Zansen B, MacMillan F, Astell-Burt T, Lonsdale C. Physical activity and school engagement in youth: a systematic review and meta-analysis. Educ Psychol. 2016 Mar;51(2):129-45. https://doi.org/10.1080/ 00461520.2016.1151793

32. Nader PR, Bradley RH, Houts RM, McRitchie SL. O'Brien M. moderate-tovigorous physical activity from age 9 to 15 years. JAMA. 2008 Jul;300(3):295305. https://doi.org/10.1001/jama.300.3.295.

33. de Meij JSB, van der Wal MF, van Mechelen W, Chinapaw MJM. A mixed methods process evaluation of the implementation of JUMP-in, a multilevel school-based intervention aimed at physical activity promotion. Health Promot Pract. 2013 Sep;14(5):777-90. https://doi.org/10.1177/15248399124 65750.

34. Webster CA, Rink JE, Carson RL, Moon J, Gaudreault KL. The comprehensive school physical activity program model: a proposed illustrative supplement to help move the needle on youth physical activity. Kinesiol Rev. 2020;9(2): 112-21. https://doi.org/10.1123/kr.2019-0048.

35. Fixsen DL, Naoom SF, Blasé KA, Friedman RM. Wallace F. Implementation Research: A Synthesis of the Literature. University of Sputh Florida, Louis de la Parte Mental Health Institute, The National Implementation Research Network, Tampa, FL; 2005.

36. Riley BL, Taylor SM, Elliott S. Determinants of implementing heart healthy promotion activities in Ontario public health units: a social ecological perspective. Health Educ Res. 2001 Aug;16(4):425-41. https://doi.org/10.1 093/her/16.4.425.

37. Greenhalgh T, Robert G, Macfarlane F, Bate P, Kyriakidou O. Diffusion of innovations in service organizations: systematic review and recommendations. Milbank Q. 2004 Dec;82(4):581-629. https://doi.org/1 0.1111/j.0887-378X.2004.00325.x.

38. McKay HA, Macdonald HM, Nettlefold L, Masse LC, Day M, Naylor P-J. Action schools! BC implementation: from efficacy to effectiveness to scale-up. Br J Sports Med. 2015 Feb;49(4):210-8. https://doi.org/10.1136/bjsports-2013093361.

39. Beighle A, Erwin HE, Castelli D, Ernst M. Preparing physical educators for the role of physical activity director. J Phys Edu Recreat Dance. 2009;80(4):24-9. https://doi.org/10.1080/07303084.2009.10598307. 
40. Franks A, Kelder S, Dino GA, Horn KA, Gortmaker SL, Wiecha JL, et al. (2015). School-based programs: lessons learned from CATCH, planet health, and not-on-tobacco. Prev chronic dis. 2007 Apr;4(2):A33.

41. Rink J, Hall T, Williams L. Schoolwide physical activity: a comprehensive guide to designing and conducting programs. Champaign, IL: Human Kinetics; 2010 .

42. Kam CM, Greenberg MT, Walls CT. Examining the role of implementation quality in school-based prevention using the PATHS curriculum. Prev Sci. 2003 Mar;4(1):55-63. https://doi.org/10.1023/A:1021786811186.

43. Adamowitsch M, Gugglberger L, Dur W. Implementation practices in school health promotion: findings from an Austrian multiple-case study. Health Promot Int. 2017 Apr;32(2):218-30. https://doi.org/10.1093/heapro/dau018.

44. Pearson M, Chilton R, Wyatt K, Abraham C, Ford T, Woods HB, et al. Implementing health promotion programmes in schools: a realist systematic review of research and experience in the United Kingdom. Implement Sci. 2015 Oct;10(1):149. https://doi.org/10.1186/s13012-015-03386.

45. Center for Disease Control and Prevention. National framework for physical activity and physical education. 2015 [cited 29 Apr 2021]. Available from: https://www.cdc.gov/healthyschools/physicalactivity/pdf/National_fra mework_Physical_Activity_and_Physical_Education_Resources_Supprt_CSPA P_508_tagged.pdf

46. Skovgaard T, Johansen DLN. Schoo-based physical activity and the implementation paradox. Advances in Physical Education. 2020 Nov; 10(04): 492-506. https://doi.org/10.4236/ape.2020.104038.

47. Belansky ES, Cutforth N, Chavez R, Crane LA, Waters E, Marshall JA. Adapted intervention mapping: a strategic planning process for increasing physical activity and healthy eating opportunities in schools via environment and policy change. J Sch Health. 2013 Mar;83(3):194-205. https://doi.org/1 0.1111/josh.12015.

48. Locke J, Lee K, Cook CR, Frederick L, Vázquez-Colón C, Ehrhart MG, et al. Understanding the organizational implementation context of schools: a qualitative study of School District administrators, principals, and teachers. School Ment Health. 2019 Sep;11(3):379-99. https://doi.org/10.1007/s12310018-9292-1.

49. Lyon AR, Cook CR, Brown EC, Locke J, Davis C, Ehrhart M, et al. Assessing organizational implementation context in the education sector: confirmatory factor analysis of measures of implementation leadership, climate, and citizenship. Implement Sci. 2018 Jan;13(1):5. https://doi.org/1 0.1186/s13012-017-0705-6.

50. Wamp Z. Creating a culture of movement: the benefits of promoting physical activity in schools and the workplace. Am J Prev Med. 2009 Feb; 36(2 Suppl):S55-6. https://doi.org/10.1016/j.amepre.2008.10.008.

51. Koch S, Troelsen J, Cassar S, Pawlowski CS. Barriers to implementation of physical activity in Danish public schools. J Teach Phys Educ. 2020;40(3):110. https://doi.org/10.1123/itpe.2019-0158.

52. Morgan PJ, Hansen V. Classroom teachers' perceptions of theimpact of barriers to teaching physical education on the quality of physical education programs. Res Q Exerc Sport. 2008 Dec;79(4):506-16. https://doi.org/10.1 080/02701367.

53. Begley C. Using triangulation in nursing research. J Adv Nurs. 1996 Jul;24(1): 122-8. https://doi.org/10.1046/j.1365-2648.1996.15217.x.

\section{Publisher's Note}

Springer Nature remains neutral with regard to jurisdictional claims in published maps and institutional affiliations.

Ready to submit your research? Choose BMC and benefit from:

- fast, convenient online submission

- thorough peer review by experienced researchers in your field

- rapid publication on acceptance

- support for research data, including large and complex data types

- gold Open Access which fosters wider collaboration and increased citations

- maximum visibility for your research: over $100 \mathrm{M}$ website views per year

At BMC, research is always in progress.

Learn more biomedcentral.com/submissions 